\title{
Garden-path sentences and executive functions in normal aging
}

\author{
Larissa Rangel Ferrari ${ }^{1}$, Erica dos Santos Rodrigues ${ }^{1}$, Daniel Correa \\ Mograbi ${ }^{2}$ \\ ${ }^{1}$ Department of Letters, Pontifical Catholic University of Rio de Janeiro, Brazil \\ ${ }^{2}$ Department of Psychology, Pontifical Catholic University of Rio de Janeiro, Brazil \\ https://doi.org/10.36505/ExLing-2019/10/0023/000385
}

\begin{abstract}
This paper investigates how the elderly process temporarily ambiguous sentences and how syntactic processing difficulties can be related to the decline of executive functions, such as working memory and inhibitory control. The study consisted of the application of a psycholinguistic experiment and neuropsychological evaluation tests. The participants were 20 older adults and 20 younger adults, who had to resolve the ambiguity in garden-path sentences, such as "While the man hunted the deer ran into the woods" (Christianson et al. 2006). The results are congruent with the hypothesis that a decreased inhibition can make it more difficult for the elderly to implement syntactic reanalysis in conditions that favour good-enough processing.
\end{abstract}

Key words: comprehension, syntax, aging, executive functions, garden-path effect

\section{Introduction}

Studies on language in normal aging have reported that the elderly tend to have more difficulty in understanding sentences of greater syntactic complexity, such as passives and sentences with embedded clauses or syntactic ambiguity (Kemper 1986, Christianson et al. 2006, Obler, et al. 1991, Zhu, Hou et al. 2018). The literature has also shown a possible correlation between difficulties in language comprehension and the decline of non-linguistic cognitive functions, such as processing speed, working memory capacity, and the ability to sustain attention and inhibit irrelevant information (Hasher, Zacks 1988, Obler et al. 1991; Salthouse 1994, Kemper, Herman 2006).

In our study, we investigated how older adults process sentences with temporary syntactic ambiguity, which induce a garden-path effect, like "While the man hunted the deer ran into the woods" (Christianson et al. 2006). In this example, the noun phrase (NP) "the deer" is the point of ambiguity, because at first it can be interpreted as the object of the subordinate clause verb ("hunted") or the subject of the main clause verb ("ran") but when the end of the sentence is reached, the only grammatically acceptable reading is to interpret "the deer" as the subject. Thus, a reanalysis process has to be performed, suppressing the syntactic representation of the critical NP as the

ExLing 2019: Proceedings of 10 $0^{\text {th }}$ International Conference of Experimental Linguistics, 25-27 September 2019, Lisbon, Portugal 


\section{L.R. Ferrari, E.S. Rodrigues, D. Correa Mograbi}

object. The resolution of the temporary ambiguity seems to place greater demands on working memory and inhibitory control.

Christianson et al. (2006) examined how older adults interpret sentences with garden-path effect and found the elderly were generally more likely to endorse the incorrect interpretation under some conditions. They concluded that the elderly may rely more on heuristic-like good-enough processing in order to compensate for a decline of working memory capacity. However, the difficulty in revising the initial incorrect interpretation may also be linked to the decline of inhibitory mechanisms, since the parser needs to inhibit the first, incorrect interpretation in order to conduct reanalysis. We expanded this approach and analysed the correlation between the participants' performance in ambiguity resolution and their performance on working memory and inhibition tests.

\section{Our study}

We applied a psycholinguistic experiment (an off-line questionnaire) and three neuropsychological tests: Digit Span, to evaluate working memory, Stroop, to evaluate inhibitory control, and Mini-Mental State Examination (MMSE), to discard participants with dementia.

\section{Participants}

The study was conducted with 40 Brazilian Portuguese speakers: 20 older adults ( 11 women, 9 men; mean age $=72.2$ ) and 20 younger adults ( 9 women, 11 men; mean age $=27.3$ ). All young adults were graduate or undergraduate students. The level of education of the elderly ranged from elementary school to college level. Only the elderly performed the MMSE.

\section{Experiment}

In the psycholinguistic experiment, two variables were taken as within-subjects: (i) the distance between the critical NP and the verb of the main clause; and (ii) the plausibility of keeping the critical NP as the object of the subordinate clause verb. Examples of sentences in each condition follow:

(1) short plausible sentence: "Enquanto o rapaz bebia a cerveja era derramada no balcão" ("While the young man drank the beer was spilled on the counter");

(2) short implausible sentence: "Enquanto a jovem bebia o vinho era mantido lacrado na adega" ("While the young woman drank the wine was kept sealed in the cellar");

(3) long plausible sentence: "Enquanto a mulher despertava o bebê que era tranquilo e sereno era picado por um inseto" "While the woman woke up the baby who was quiet and serene was bitten by an insect"); 
(4) long implausible sentence: "Enquanto o homem despertava a mulher que era jovem e tranquila era agredida no trabalho" ("While the man woke up the woman who was young and quiet was assaulted at work").

\section{Materials and procedure}

Stimuli consisted of 32 experimental sentences and 28 fillers, randomly presented. There were 8 trials for each of the 4 conditions. The fillers consisted of active and passive sentences and with perspective verbs.

The sentences were presented separately on a notebook screen. Participants could only read each sentence twice. They had to answer questions with "yes" or "no" after reading each sentence. The questions related to whether the participant had retained the analysis of the critical NP as the object (e.g. "Did the man hunt the deer?" for the sentence "While the man hunted the deer ran into the woods").

\section{Results}

The data was analysed using the Statistical Package SPSS 23, and a variance analysis (ANOVA) was applied to the hit rate results. T-tests were used to compare the performance on the Digit Span test and Stroop test. The Pearson correlation coefficient $(r)$ was applied to identify possible correlations between the linguistic factors and the executive functions.

The elderly performed worse than young adults on the Digit Span test, on the direct digit order phase $(p=.011)$ and on the reverse digit order phase $(p=$ $.023)$. On the third phase of the Stroop test, the elderly also presented worse results than the young adults $(p=.011)$. The task execution time for the Stroop test was significantly longer for the elderly $(p<.001)$.

The results showed a main effect of plausibility $[\mathrm{F}(1.38)=87.37 ; p<.001]$ and a main effect of extension of the ambiguous region $[\mathrm{F}(1.38)=18.61 ; p$ $<.001]$. An interaction effect was also observed between plausibility and group $[\mathrm{F}(1.38)=7.99 ; p=.007]$. From the pairwise comparisons, the difference in performance between the groups was only significant on the plausible condition $(p=.035)$. The elderly performed better on the implausible than the plausible conditions. In view of the differences in the participants' level of education, a covariance analysis (ANCOVA) was performed, with the inclusion of education as a covariate. The interaction effect between plausibility and group remained $[\mathrm{F}(1.37)=9.46 ; p=.004]$.

A positive correlation was observed between age and number of errors in the third phase of the Stroop test $(r=.35 ; p=.05)$; between age and task execution time in the Stroop test $(r=.58 ; p=.01)$; and between age and task execution time in the third phase of the Stroop test $(r=.68 ; p=.01)$. There was also a negative correlation between plausibility and number of errors in the third phase of the Stroop test $(r=-.33 ; p=.05)$; between plausibility and task 


\section{L.R. Ferrari, E.S. Rodrigues, D. Correa Mograbi}

execution time in the third phase of the Stroop test $(r=-.36$; $p=.05)$; between plausibility and age $(r=-.44 ; p=.01)$; between age and performance in the direct digit order phase $(r=-.40 ; p=.05)$; and between age and performance in the reverse digit order phase $(r=-.38 ; p=.05)$ of the Digit Span test.

\section{Discussion}

As we predicted, solving the ambiguity in the plausible and the long conditions was more complex for both groups of participants. However, the older participants performed significantly worse on the plausible condition and on the Stroop test than the younger participants.

These data and the correlation between plausibility and the performance on the Stroop test suggest that a decline in inhibition in aging may have hindered implementation of a full syntactic reanalysis in the plausible condition. The elderly may tend to implement a good-enough processing strategy, based on pragmatic knowledge. Moreover, the correlation between age and performance on the Digit test converges with the literature, which reports that aging is accompanied by a decline in working memory.

\section{References}

Christianson, K., Williams, C.C., Zacks, R.T., Ferreira, F. 2006. Younger and older adults' "good-enough" interpretations of garden-path sentences. Discourse processes, 42, 205-238.

Hasher, L., Zacks, R. 1988. Working memory, comprehension and aging: a review and a new view. In Bower, G. K. (ed.). The psychology of learning and motivation. New York: Academic Press, 192-225.

Kemper, S. 1986. Limitation of complex syntactic constructions by elderly adults. Applied Psycholinguistics, 7, 277-288.

Kemper, S., Herman, R.E. 2006. Age differences in memory-load interference effects in syntactic processing. J. Gerontol. Ser. B Psychol. Sci. Soc. Sci. 61, 327-332.

Obler, L.K., Fein, D., Nicholas, M., Albert, M.L. 1991. Auditory comprehension and aging: decline in syntactic processing. Applied Psycholinguistics, 12, 433-452.

Salthouse, T.A. 1994. The aging of working memory. Neuropsychology 8, 535-543.

Zhu, Z., Hou, X., Yang, Y. 2018. Reduced Syntactic Processing Efficiency in Older Adults During Sentence Comprehension. Frontiers in Psychology 9, article 243. 